\title{
POST-FLEDGING MOVEMENTS OF JUVENILE BALD EAGLES
}

\author{
PETER GERRARD ${ }^{a}$ JONATHON M. GERRARD ${ }^{b}$ \\ DOUGLAS W. A. WHITEFIELD ${ }^{\mathrm{c}}$ and WILLIAM J. MAHER ${ }^{\mathrm{d}}$
}

\begin{abstract}
The knowledge of post-fledging movements by Bald Eagles which we report in this article was obtained with the aid of a technique which we used for the first time in 1973. This involves the placement of one or several pieces of brightly coloured vinyl cloth around the birds' wings, as shown in Figure 4. These markers, when properly applied, do not hamper the birds' movements but make them individually identifiable. Several people in Saskatchewan and in northern states reported sightings of marked birds. This past summer (1974) we marked most of the young fledged at Besnard Lake in the same fashion. We ask that anyone who sees a young Bald Eagle with coloured cloth on its wings to report this observation to one of the authors. The information which we would like to receive is the sequence of colours on each wing, the date, time and place of sighting.
\end{abstract}

Young Bald Eagles, as with diurnal birds of prey, remain dependent on their parents for some time after they leave the nest. In this period of transition, the young eagles must acquire enough skill at both flying and food gathering to survive on their own. As a step towards understanding this phase of the eagle's development, we made a study of the distances from their nests to which fledglings wander, prior to and including the time of migration.

Study area - Besnard Lake is situated at Lat. $55^{\circ} 24^{\prime} \mathrm{N}$ on the southern edge of the Precambrian outcroppings, approximately 35 miles northwest of La Ronge, Saskatchewan. It is about 62 square miles in area with an irregular shoreline approximately 250 miles long. It has many islands.

(a)808-880 Cambridge St., Winnipeg, Manitoba. (b) 954 - 15th Ave. S.E., Minneapolis. Minnesota. (c) University of Alberta, Edmonton, Alberta.

(d) University of Saskatchewan, Saskatoon,

Saskatchewan.
Methods - In 1973, there were 26 or 27 Bald Eagle breeding areas on Besnard Lake. Eighteen of the young in 13 nests were individually marked with different combinations of red, yellow or green vinyl wing markers. The method was previously used successfully on Golden Eagles by Kochert."

The age of the marked young was estimated from our April observations of nests and assuming a 35-day incubation period.' Later, at the time it was marked, each nestling was weighed and its wing and tail feathers were measured. A final estimate of the age was made by subjectively taking these measurements into account.

The age estimates are complicated by uncertainty regarding the incubation period" and individual variation in size. We consider the age estimates to be reliable within 5 days. Hatching spanned 5 weeks in the Besnard Lake eagle population so that 


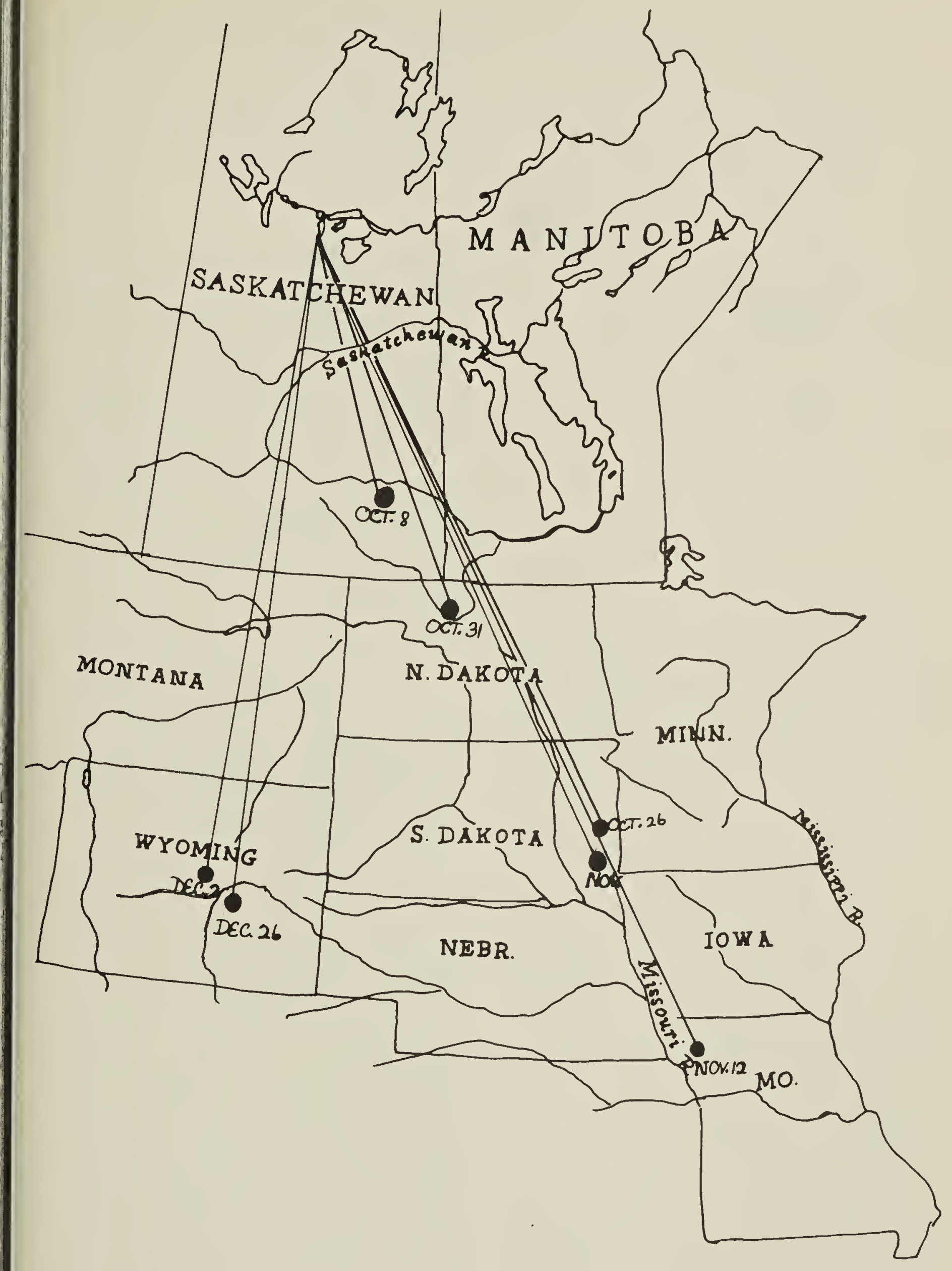

Fig. 1. Sightings of wing-marked Bald Eagles after they had left Besnard Lake.

there was considerable discrepancy in the age of young at any one time.

The status of young at the nests was checked frequently from a boat in July,
August and September. The distance and direction of each young eagle from its nest was noted when it was first seen and identified. If an immature eagle 


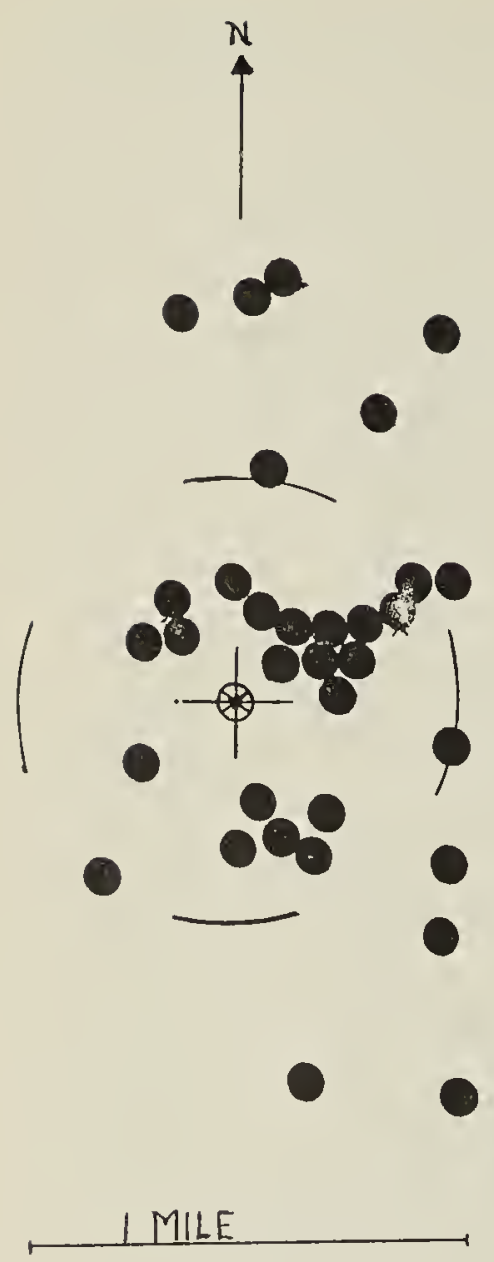

Fig. 2. Distance and direction from the nest of all sightings of Bald Eagle young at Besnard Lake.

was seen more than once in a day, only observations at least 6 hours apart were used. If a young eagle was not seen on a survey it was recorded as "not found". An immature eagle that was not found could have been on the ground, perched in a tree and concealed from our view, on a part of the lake not surveyed or away from Besnard Lake. Marked young which could not be identified clearly were not recorded and would then be included among those "not found".

In addition to nest surveys, the events at one nest were recorded by time-lapse photography. A super-8 mm movie camera, set to take one frame every 4 minutes, was mounted about 45 feet from a nest, (Nest S). It was installed when the young were 3 to 4 weeks old and it was maintained until August 17, 9 days after the second and last young had fledged.
Wind direction and estimated speec were recorded three times daily: mor ning, early afternoon and evening These records were used to assess the relationship between wind and the movements of young eagles away from the nest.

Results - Most young fledged in the 2nd and 3 rd weeks of August and stayed within 1.5 miles of the nest until the end of September (Table 1). A preliminary examination of our data showed that both early fledging and carly apparent departure from the lake seemed to correlate with early hatching. Since we were interested in correlating the eagles' ages with their post-fledging movements, we have converted our data to weeks after hatching. (Table 2).

Most young were on the nest when first seen up to the end of the 11 th week. Probably most of these had not yet fledged but some could have already left the nest and returned. Records of movements of young from one nest show that some young return to the nest platform up to 6 weeks after fledging (Table 3). Most young fledged in their 12 th or 13 th weeks. This was a little later than in 1972 when young generally fledged during the 10th, 11 th and 12 th weeks:3 and suggests that the exact timing of fledging may be somewhat variable, perhaps depending on the weather at fledging time or on the food supply during nestling period. The majority of young seen in their 12 th to 14 th weeks were either on the nest (42 percent) or within 1/8 mile of it ( 32 percent, Table 2). A few (17 percent), however had wandered $1 / 3$ to $1 / 2$ mile from the nest and 9 percent had moved even farther. At this age the young generally perched in trees but a few ( 11 percent) were seen on the ground. Dark brown young eagles are fairly well camouflaged on such low perches and 
Table 1 .

Distances of young Bald Eagles from the nest in 1973 as a function of date.

Date

$\ln$

Nest Miles from nest

Tree $1 / 8>1 / 8-1 / 4>1 / 4-1 / 2>1 / 2-1>1$ found $300+$ Total

Aug. $1-7$

Aug. 8-14

Aug. 15-21

Aug. 22-28

Aug. 29-

Sept. 4

Sept. $5-11$

Sept. 12-18

Sept. 19-25

Sept. 26 -

Oct. 2

Oct. $3-10$

Oct. 25-31

20

$\begin{array}{llll}6 & 3 & & 1 \\ 5 & 5 & 1 & 3 \\ 4 & 5 & 2 & 2\end{array}$

$\begin{array}{rr}1 & 21 \\ 5 & 15 \\ 11 & 28 \\ 5 & 20\end{array}$

Nov. $8-14$

often difficult to see. This probably accounts for the 36 percent of the known young which were not found.

In the 15 th to 17 th weeks, 3 to 4 weeks after fledging, 28 percent of young actually seen were within $1 / 8$ mile of the nest and only 21 percent were on the nest itself. The reduced proportion of the young at the nest when first seen, compared with the 12 to 14-week old young, reflected a decreasing but continuing use of the nest for a perch, a feeding station or a roosting site. Fifty percent of the young seen were more than $1 / 8$ mile

Table 2.

Distances of young Bald Eagles from the nest in 1973

as a function of age.

\begin{tabular}{|c|c|c|c|c|c|c|c|c|c|}
\hline $\begin{array}{l}\text { Weeks } \\
\text { after } \\
\text { hatching }\end{array}$ & $\begin{array}{l}\text { In } \\
\text { Nest } \\
\text { tree }\end{array}$ & $1 / 8$ & $\begin{array}{c}\text { Miles } f \\
>1 / 8-1\end{array}$ & $\begin{array}{l}\text { nest } \\
1 / 4-1 / 2\end{array}$ & $>1 / 2-1$ & $>1$ & $\begin{array}{l}\text { Not } \\
\text { found }\end{array}$ & $300+$ & Tota \\
\hline 9 & 24 & 1 & & & & & & & 25 \\
\hline 10 & 8 & & & & & & & & 8 \\
\hline 11 & 21 & & & & & & 1 & & 22 \\
\hline 12 & 8 & 4 & & & & & 6 & & 18 \\
\hline 13 & 4 & 6 & 2 & 1 & & 1 & 8 & & 22 \\
\hline 14 & 5 & 3 & & 4 & 2 & 1 & 9 & & 24 \\
\hline 15 & 1 & 3 & 2 & 1 & 1 & 3 & 3 & & 14 \\
\hline 16 & 1 & 2 & & & & & 3 & & 6 \\
\hline 17 & 4 & 3 & 3 & 1 & & 3 & 4 & & 18 \\
\hline 18 & 1 & 6 & 2 & & 1 & 1 & 6 & & 17 \\
\hline 19 & & & 2 & & & & 6 & & 8 \\
\hline 20 & 1 & 3 & 2 & 2 & 4 & & 9 & & 21 \\
\hline 21 & & & & & 2 & & 14 & 1 & 17 \\
\hline 24 & & & & & & & & 2 & 2 \\
\hline 26 & & & & & & & & 1 & 1 \\
\hline
\end{tabular}


Table 3.

Records of movements of two young Bald Eagles and adults at Nest $\mathrm{S}$ during fledging period.*

Dite

July 30

Aug. 8

Aug. 9

Aug. 10

Aug. 12-15

Aug. 17

\section{Visited nest}

briefly while youngest eaglet fed.

Left nest in morning.

Young eaglet

Adults

Left nest and was then on and off nest periodically during the day.

Roosted on nest.

Left nest in late afternoon.

Visited nest briefly in the evening.

Spent most of the time on nest during the day. On nest in early morning, then left. Returned to eat fish brought in by adult.

Adult brought a fish to the nest about midday.

Adult brought a fish to the nest in the morning, stayed about 20 minutes, then left.

Adult brought a fish to nest, stayed about 1-1/2 hours, then left when younger eaglet returned.

Seen flying over nest area.

Aug. 20

Aug. 27

Sept. 11

Sept. 19

Sept. 26

Oct. 2

Perched near top of spruce tree $1 / 2$ mile east of nest.

\section{On nest.}

1/4 mile NE of nest.

$1 / 4$ mile NE of nest.

Not seen.
1/8 mile SW of nest.

On nest.

$1 / 4$ mile NE of nest.

$1 / 4$ mile NE of nest.

$1 / 4$ mile NE of nest.
Two adults near nest.

Adult near nest. Two adults near nest.

Adult near nest.

*Includes all observations of two fledged young at Nest S from 30 July and all observations of adults after August 8. Observations to August 17 are based on time-lapse photographs. Observations after August 17 were made on visits to the nest.

from the nest. During this period, the young tended to perch higher in the trees than they did earlier, where they were conspicuous, and only 26 percent of the known young were not found.

In the succeeding weeks there was a general movement away from the nests, although even as late as the 20th week one young was seen perched within a few feet of its nest. In the 18 th to 20 th weeks, 6 to 7 weeks after fledging, the use of the nest continued to decline with only two young ( 8 percent of those seen) on it. Most of the young, however, remained within 1 $1 / 2$ miles of the nest with 36 percent of those seen still within $1 / 8$ mile of the nest and 56 percent between $1 / 8$ and 1 mile of the nest. The proportion of young not found (45 percent of the known young) was higher than in the previous age groups, probably reflec- 


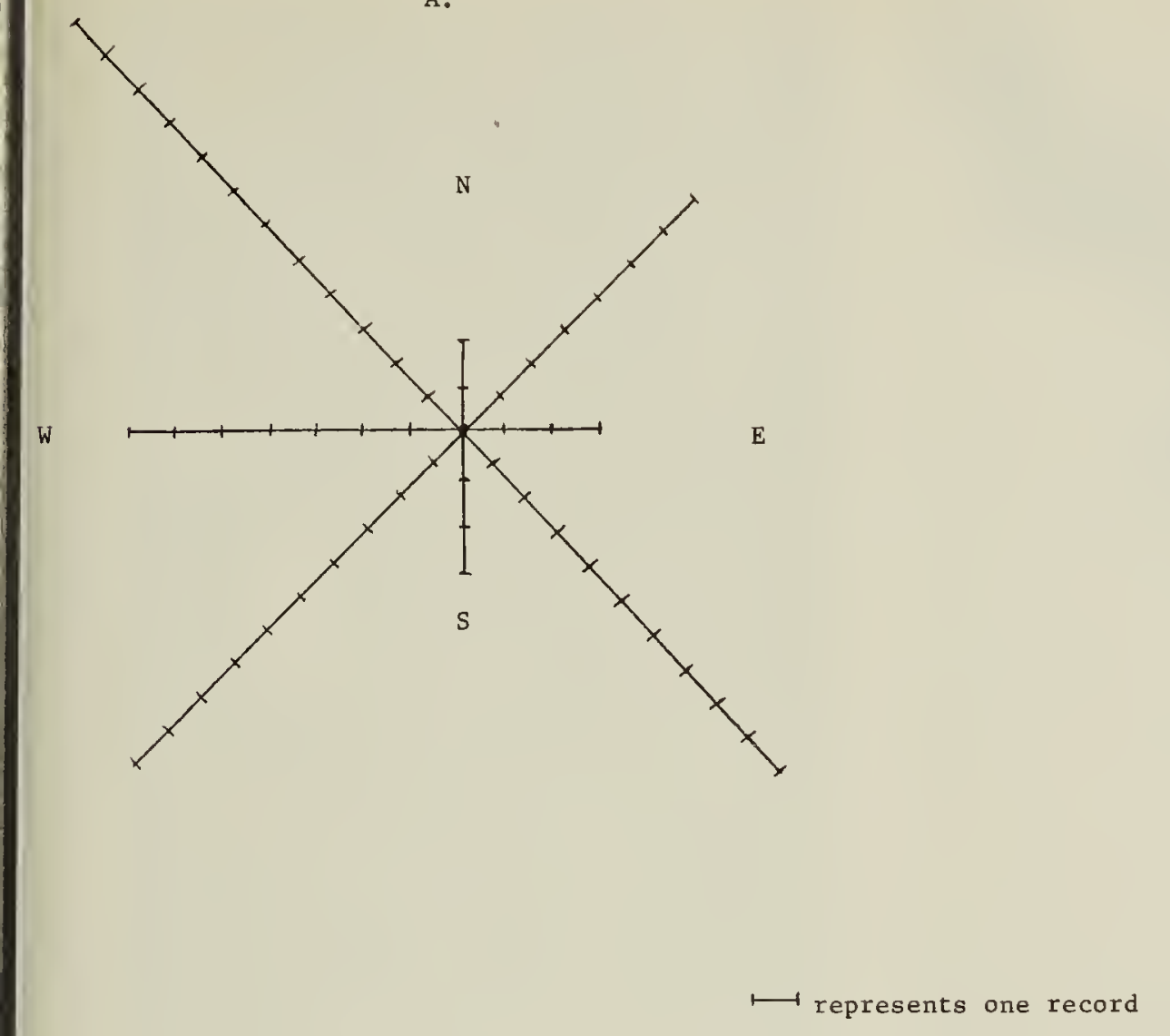

Fig. 3. Cumulative records of wind speed and direction at Besnard Lake in 1973. A. Winds over $5 \mathrm{mph}$. B. Winds over $10 \mathrm{mph}$.

ting the beginning of the movement off the lake to areas where we could not observe them. One of the young found near the nest during this period was on the ground unable to fly. Later evaluation showed a healed fracture of one wing. This bird had been found off the nest in its 9th week, 3 weeks earlier than most other young, and had probably sustained the fracture in its initial fall from the nest. It was healthy in other respects and had clearly been well fed by its parent. This bird was sent to Montreal to participate in a breeding project.

The first indication of general movement of young eagles off the lake was in the 21 st week. Only two of 16 young thought to be on Besnard Lake were found. At the same time Glen Scott, of Indian Head, Saskatchewan, spotted a young eagle in its 2 Ist week about 350 miles south southeast of Besnard Lake. Six later reports gave more information on the movement southward (Fig. 1).
Analysis and Discussion - In analyzing the movement of the young eagles away from the nest we were intrigued by a tendency for them to move east and north (Fig. 2). When we analyzed this movement statistically we found that it was not random (chi-square test, $\mathrm{P}<0.001$ ). It remained non-random even if we treated as one all the sightings of one young (see below) which moved to an area northeast of the nest (chi-square test, $\mathrm{P}<0.01$ ). Six sightings of this young were omitted because its perch could be seen from our camp island and we could see no other young from this point.

We had noted that subadult Bald Eagles (ages 2-4 years) summering on Besnard Lake tended to drift downwind when moving around the lake, ${ }^{4}$ and we wondered if wind direction might also influence the movements of the fledged young. On the assumption that light winds would have little effect on eagle movements, we analyzed separately all winds greater than 5 


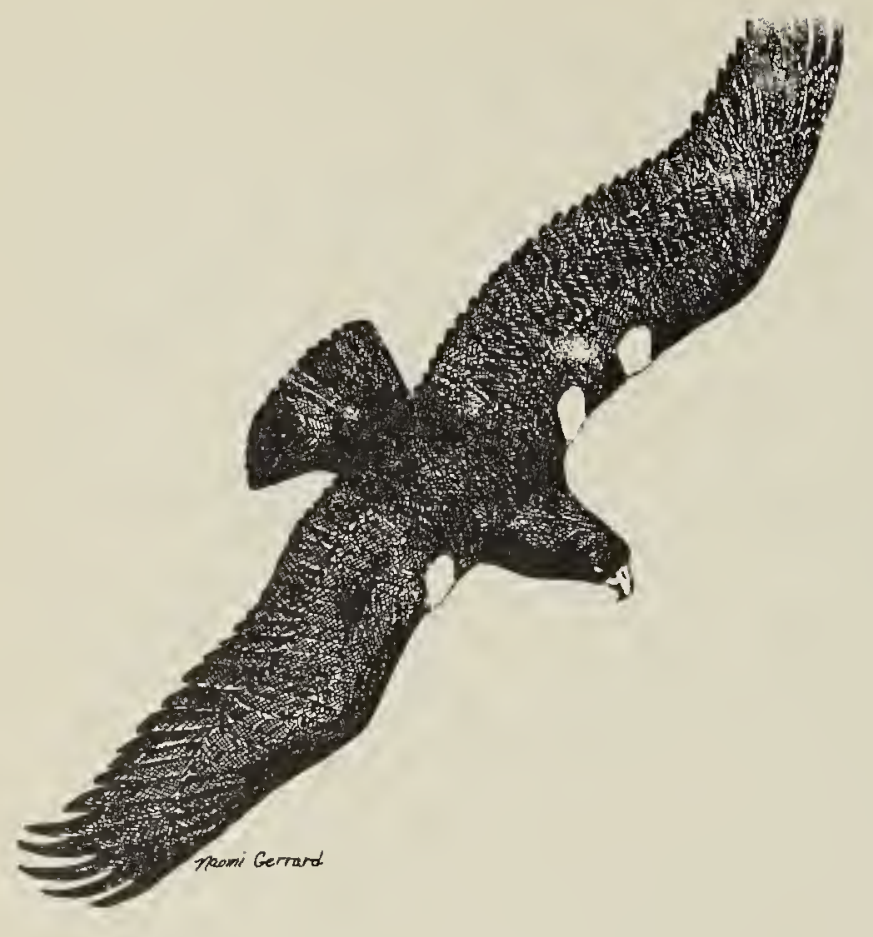

Fig. 4 Wing markers as seen from above.

m.p.h. and all winds greater than 10 m.p.h. (Fig. 3). In each case, we grouped sightings of eagles into the eight major compass points $\pm 45^{\circ}$, and matched these with winds blowing in the same directions. The results suggested a highly significant association between winds greater than 10 m.p.h. and the directions the young eagles moved $(r=0.85, \quad D F=6$,
$\mathrm{P}<0.01)$. This seems to suggest that th nest bond of young eagles in the im mediate post-fledging perior gradually weakens and that, in the ab sence of any purposive migratory orientation, their movement from the nest is influenced by the wind. Young eagles appear to be carried away from the nest by strong winds and lacking definite drive to return to the nes: when the wind dies they are gradually distributed downwind from it. The actual direction of movement is also influenced by the direction of the shoreline since the birds tend to follow shorelines rather than move overland.

One observation made on August 3, 1972, by A. Moulin and N. Gerrard supports this thesis. They were watching two recently fledged young at a nest with a stiff breeze blowing from the northeast (about $15 \mathrm{mph}$ ). At 11:01 hours, one of the immatures began circling over the north end of its nest island. Very quickly it gained height and drifted off to the west. If it had gone directly downwind, southwest, it would have left the lake, whereas in

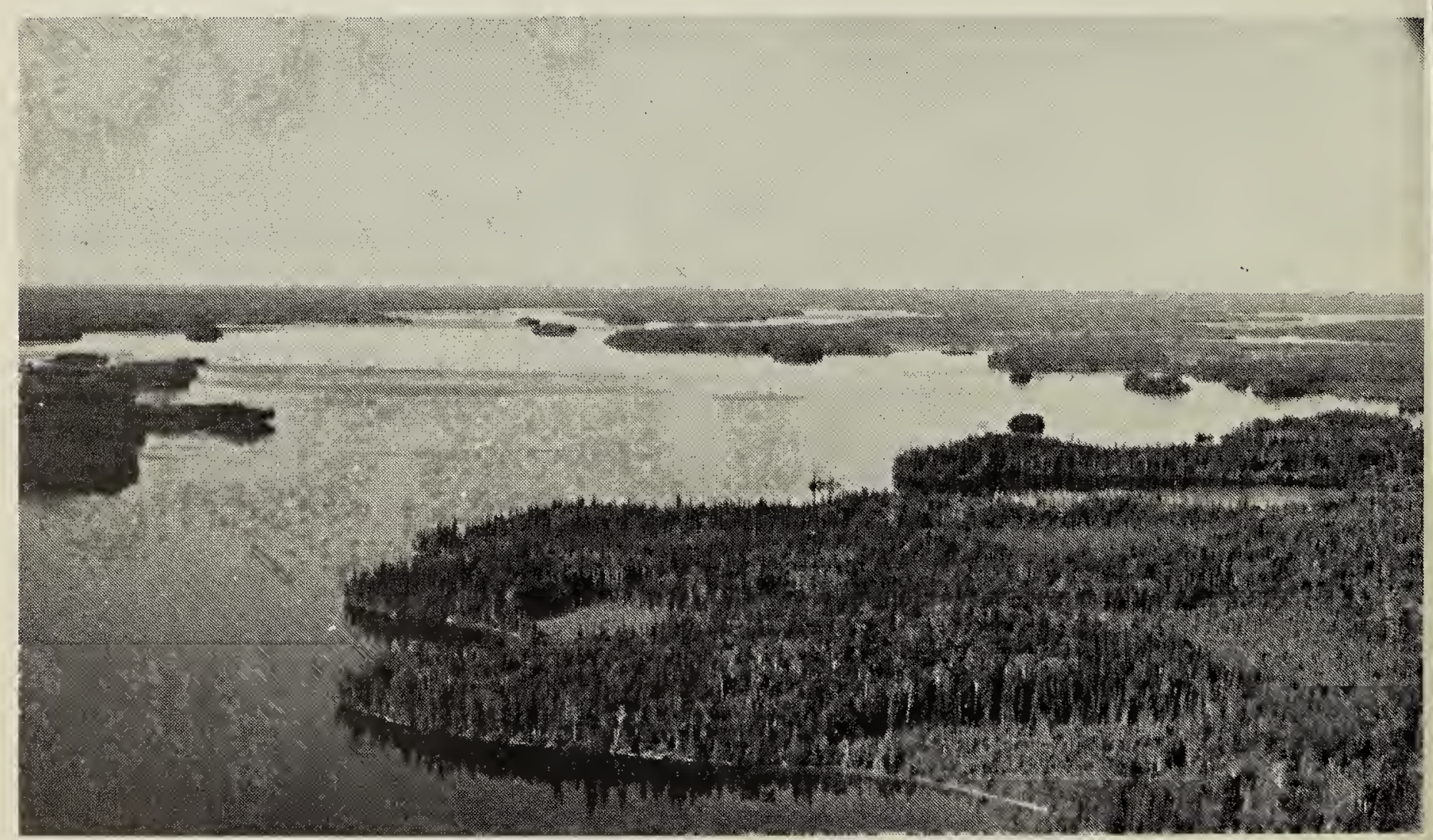

Fig. 5. An acrial view of Besnard Lake showing characteristic irregular shoreline and small islands. 


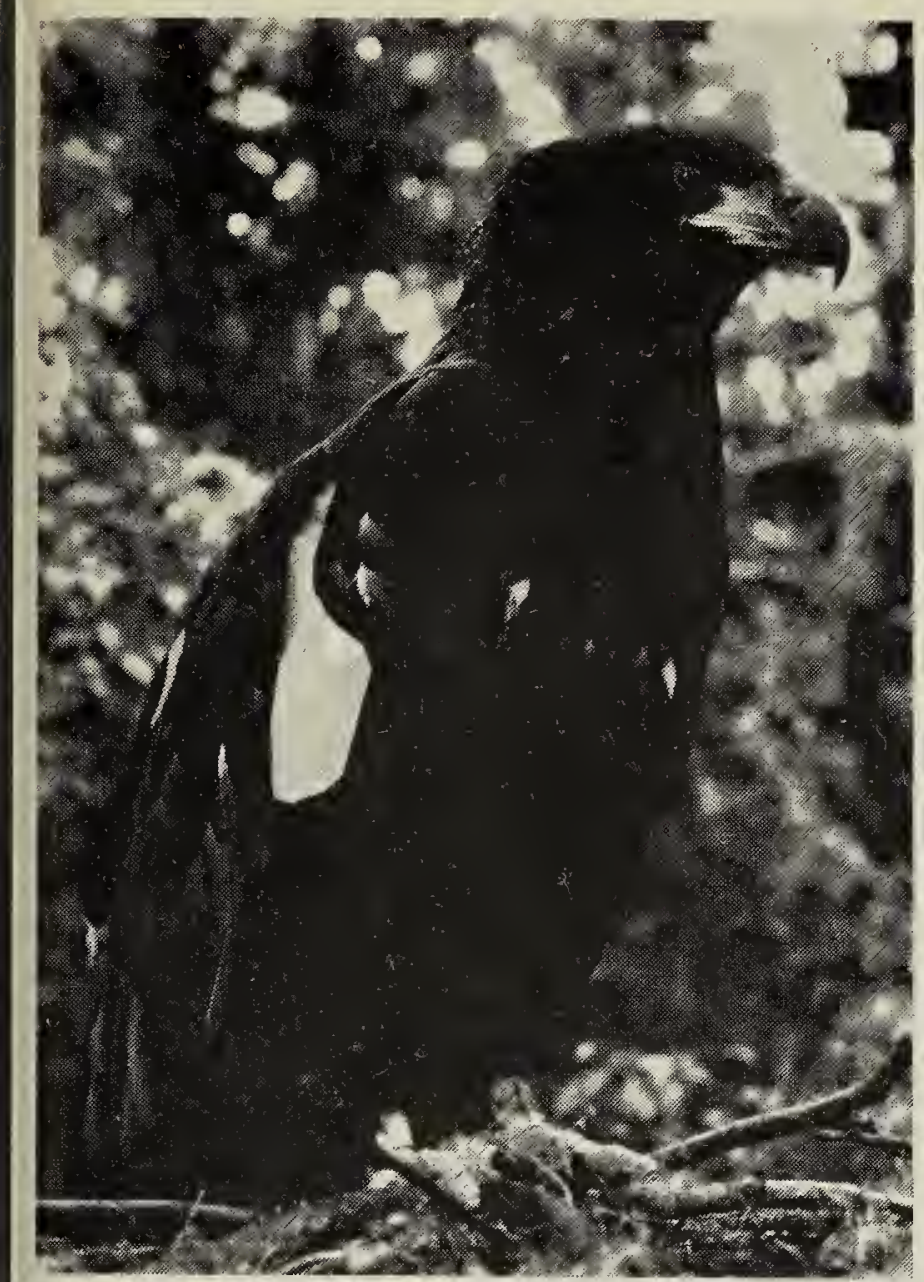

Fig. 6. A young eagle 10 weeks old with two markers on the right wing. The outer marker is easily visible. A small part of the inside marker can be seen just behind the outside marker.

deviating to the west, it followed a channel of the lake. It was not until 3 weeks later (August 27) that two young were again seen near this nest, although the area was watched for 4 hours on August 13, and 9 hours on August 18. Knowing the difficulty that the young had in landing and in flight on August 2, it was thought that this young would have had difficulty in returning to the island once it was soaring on the strong wind of August 3. The implications of this observation for movements of young eagles in the post-fledging period were not appreciated until later.

It is apparent from observations of one young at another nest, that wind is not the only reason for movements of young. On August 12, this bird flushed from the nest and flew at a right angle to the wind to a small island 1.4 miles east-northeast of its nest island. It was observed on this island from time to time until September 21. Attachment may develop for a particularly suitable perch site after fledging and such places, once visited and "learned" by a young bird, may be more frequently visited thereafter.

The waning attachment of young eagles for the nest site and the tendency for gradual downwind dispersal from the nest is replaced in the 20th and 21 st weeks by oriented migratory movement. The seven sightings of marked young eagles (Fig. 1) indicate this and suggest a relatively slow southward movement.

Summary and Conclusions - Fledged young Bald Eagles have a strong nestsite bond which gradually weakens as they mature. By the 3 rd or 4 th week after fledging, half of the young seen were more than $1 / 8$ mile from the nest. Most young were within 1 mile of their nests through their 20th week, 7 weeks after fledging. Movement away from the nest in this period tended to be east and north. The direction of movement correlates with direction of winds over 10 miles per hour and suggests that as their nest-site bond weakens, young eagles take the course of least resistance and drift downwind and tend to follow the lake shore. In the 7 th to 8 th weeks after fledging, when chicks are in their 21 st week, a strong migratory drive develops and the birds depart from Besnard Lake.

\section{Acknowledgements}

Our studies were supported financially by the Canadian Wildlife Service, Environment Canada, and the Saskatchewan Department of Natural Resources. The following contributed observations of wing-marked eagles: Rob Hernandez, Alex Farley, Allan Moulin, Joe Daly, Naomi Gerrard, Nikke Higgins, John Hastings, Cory 




Fig. 7. The same young eagle seen in Fig. 6, showing the wing marker on the left wing. This marker is close to the body and has been preened by the eagle so that it is only barely visible.

Siemans, Glen Scott, Don Perchuchin, Mrs. Harvey Mills, Terry DeBeer, Bruce Wolhunter, W. C. Foss, C. Upton and $\mathrm{J}$. Hutchinson.

'BENT, A. C. 1937. Life Histories of North American birds of prey, Part I. Republished 1961, Dover Publieations, New York, N.Y.

'BROWN, L., and D. AMADON, 1968. Eagles, hawks and falcons of the world, MeGraw-Hill Book Co., New York, N.Y.
GERRARD, J. M., P. N. GERRARD, D. W. A. WHITFIELD, and W. J. MAHER, 1973. Bald Eagle behaviour study part II. Final report to Canadian Wildlife Service on eontraet CWS7273-43. 90pp. (mimeo).

${ }^{4}$ GERRARD, P., D. W. A. WHITFIELD, J. M. GERRARD, and W. J. MAHER. Bald Eagle behaviour study, part III. (In preparation).

HOCHBAUM, H. A. 1955. Travels and tradilions of waterfowl, University of Minnesota Press, Minneapolis, Minn. 301 pp.

"KOCHERT, M. N. 1974. Evaluation of a vinyl wing-marker for raptors, in the Proc. Conf. on Raptor Conservation Teehniques, Mareh 22-25, 1973, Fort Collins, Colorado, in press. 